\title{
Itinerarios terapéuticos de mujeres migrantes de origen boliviano en la ciudad de Buenos Aires
}

\section{Pablo Buzzi}

(iD) https://orcid.org/0000-0001-7900-6955

Instituto de Salud Colectiva (ISCo)

Universidad Nacional de Lanús (UNLa)

buzzipablo@yahoo.com.ar

\author{
Anahí Sy \\ https://orcid.org/0000-0002-1281-5333 \\ Instituto de Salud Colectiva (ISCo) \\ Universidad Nacional de Lanús (UNLa) \\ CONICET \\ anahisy@gmail.com
}

\section{RESUMEN}

Este trabajo tiene como objetivo describir y analizar los itinerarios terapéuticos de las mujeres migrantes de origen boliviano en los barrios de Bajo Flores y Villa 31, de la Ciudad Autónoma de Buenos Aires. Se utilizó metodología cualitativa, orientada a indagar sobre las estrategias de atención a la salud, aplicando las técnicas de entrevista y grupo focal. Como principales resultados, se registra el uso articulado de diversas formas de atención, en particular, es frecuente la consulta al farmacéutico en reemplazo del médico, y a sea como forma de evitar los obstáculos y barreras del sistema público de atención o como alternativa ante el fracaso terapéutico de decisiones previas. Además, en el trabajo se describen las barreras que estas mujeres encuentran al intentar acceder al sistema público. Por último, se observa que la circulación de información entre familiares, vecinos, amigos y "paisanos» se convierte en el medio más frecuente de acceso a conocimientos sobre las alternativas de atención disponibles en cada territorio. 
Palabras clave: atención a la salud; mujeres; migración; accesibilidad a los servicios de salud; itinerarios terapéuticos.

\title{
Therapeutic Itineraries of Female Migrants from Bolivia in the City of Buenos Aires
}

\author{
ABSTRACT
}

This paper aims to describe and analyze the therapeutic itineraries of female migrants from Bolivia residing two neighborhoods of Buenos Aires, "Bajo Flores" and "Villa 31". Qualitative methodology, using techniques of interviews and focus groups, oriented the investigation of health care strategies. As a principle result, we identified the articulation of various healthcare systems, particularly that of frequent consultation of pharmacists as substitution for physicians, be this a form of avoiding the barriers and obstacles of access to the public health system or as an alternative to previous therapeutic failures. In addition, the barriers that these women encounter when trying to access care in the public health system are described. Finally, we observed that the circulation of information among family members, neighbors, friends and "countrymen" is the most frequent means of accessing knowledge about the available care alternatives in each territory.

Keywords: Health-care system, women, migration, health services accessibility, therapeutic itineraries. 


\section{INTRODUCCIÓN}

La Argentina ha sido históricamente un país receptor de migración. De hecho, se trata del proceso constitutivo de la Nación. Hasta la década de 1980, la mayor parte de los migrantes provenía de Europa, especialmente de España e Italia; a partir de ese momento, tuvo lugar un progresivo aumento de la población procedente de los países de la región hasta constituirse en casi el 70\% del total de migrantes arribados al país. Gran parte de ese aluvión migratorio se estableció en el Área Metropolitana de Buenos Aires (AMBA), donde reside casi el 60\% de la población migrante reconocida censalmente en el país. En el caso específico de la Ciudad Autónoma de Buenos Aires (CABA), en el año 2010 los migrantes de origen boliviano constituyeron el segundo grupo poblacional numéricamente más importante del total de la población nacida en el extranjero, solo superado por los provenientes del Paraguay. Dos de los barrios con mayor concentración de población de este origen son Bajo Flores y Villa 31.

La presencia de gran cantidad de personas de diversos orígenes y su concentración espacial en diversas zonas de la CABA plantea desafíos no solo relacionados con lo socioeconómico, sino que también representa un reto en lo que se refiere a las estrategias para planificar la atención y los programas de prevención y promoción de la salud. En este sentido, surgen algunos interrogantes: ¿cuáles son las prácticas de los migrantes de origen boliviano ante un problema de salud? ¿Cómo resuelven sus problemas de salud quienes no pueden o no quieren consultar en los servicios públicos de salud y de qué manera se articulan e incluyen prácticas alternativas de atención a la salud al sistema de atención establecido oficialmente? El objetivo de este trabajo es encontrar respuestas a esos interrogantes a partir de las narraciones de mujeres migrantes acerca de sus experiencias ante un padecimiento o enfermedad.

La elección de las mujeres como informantes clave se debe a que ellas, tal como señalan diversos autores (Menéndez, 1994, 2005; Merino y Marcon, 
2007; Perdiguero y Tosal, 2007;), son las encargadas de realizar la mayoría de las actividades relacionadas con el proceso salud/enfermedad/atención (PSEA) en el hogar (detectar, diagnosticar, establecer los primeros tratamientos, búsqueda de ayuda, etcétera), lo que ha llevado a referir una división del trabajo dentro del grupo familiar. Es a partir de ese rol de cuidadora informal que adquiere gradualmente saberes y experiencias en todo lo referido al PSEA, así como una mayor sensibilidad a la detección de síntomas o malestares en el ámbito doméstico. Es en ese sentido que consideramos clave acceder al conocimiento que poseen estas mujeres migrantes sobre las estrategias que desarrollan para solucionar o acompañar la resolución de problemas de salud propios, de algún familiar o allegado, las contingencias y dificultades que enfrentan a diario en esa tarea.

Los padecimientos y problemas de salud (así como las acciones para hacerles frente) son eventos continuos y recurrentes e inseparables de la experiencia humana que afectan la vida cotidiana de los sujetos y conjuntos sociales, y forman parte de un proceso social dentro del cual se establece colectivamente la subjetividad (Menéndez, 1994).

El concepto de itinerarios terapéuticos constituye una aproximación al mencionado proceso en los sujetos o grupos sociales ya que permite conocer las prácticas y reflexiones a partir de sufrir algún padecimiento. Refiere a las diversas decisiones y acciones llevadas adelante por las personas en presencia de un problema de salud, que involucran (en ocasiones de manera simultánea) diversos saberes y formas de intervención sobre dichas afecciones (Cabral, Martínez-Hernáez, Andrade y Cherchiglia, 2011; Mattosinho y Silva, 2007). En ese recorrido, el enfermo entra en relación con diferentes actores (su familia, los vecinos/comunidad, diversos curadores, instituciones, etcétera), entablando interacciones de gran relevancia para la comprensión de la selección entre las diferentes opciones de tratamiento (Martins, 2008; Trad, Tavares, Soares y Ripardo, 2010; Venturiello, 2012).

Gerhardt (2006) indica el modo en que las informaciones y experiencias acumuladas por el grupo familiar, que combinan concepciones biomédicas y saberes populares, entran en juego a la hora de evaluar la seriedad del padecimiento y el peso que las relaciones sociales, las instituciones y las representaciones colectivas tienen en la elaboración de los discursos sobre la enfermedad. Al considerar las relaciones sociales, se debe tener en cuenta que en toda sociedad hay una distribución desigual de recursos y poder y que la población migrante en la CABA está confinada a los sectores más bajos de la estructura social, con dificultades en el acceso a vivienda y trabajo dignos, además de situaciones de discriminación que condicionarán el desarrollo de sus recorridos. 
La comprensión de los itinerarios terapéuticos requiere tener en cuenta varios aspectos: (i) el primer diagnóstico que el propio afectado hace sobre su problema y su pronóstico del mismo; (ii) la disponibilidad y accesibilidad a las diferentes alternativas de atención; (iii) la experiencia con cada opción seleccionada, y (iv) la evaluación de los resultados obtenidos en esas experiencias. Tal como destacan Trad y otros (2010), estos recorridos involucran hábitos y acciones imprevistas, por lo que no puede establecerse un modelo para clasificar los procesos de selección. Cada uno de ellos deber ser comprendido en el contexto individual, cultural $y$ de relaciones en el que tiene lugar.

En lo relativo a las alternativas de atención disponibles, Menéndez (2003, 2005, 2009) señala que las condiciones sociales, económicas, políticas, religiosas, étnicas y de desarrollo científico-tecnológico que caracterizan una sociedad dada constituyen el marco en el que se desarrollan y existen las diversas posibilidades. En esta coexistencia se plantean relaciones de hegemonía/subalternidad, plasmadas en distintos grados de visibilidad y de adhesión por los distintos actores sociales, donde lo más frecuente es lo que se conoce como pluralismo médico, es decir, la coexistencia antagónica y a la vez complementaria de diversas formas de atención utilizadas muchas veces en forma simultánea (Menéndez, 2005, 2009).

La autoatención y la biomedicina son las formas de atención más difundidas en las sociedades occidentales (Menéndez, 1994, 2003, 2005, 2009). La primera es la actividad nuclear y sintetizadora de las diversas alternativas que los sujetos y grupos sociales llevan adelante en relación con el PSEA para diagnosticar, explicar, atender, controlar, aliviar, aguantar, curar, solucionar o prevenir los procesos que afectan a la salud en términos reales o imaginarios, sin la intervención central, directa e intencional de curadores profesionales, aun cuando éstos sean la referencia. La biomedicina se caracteriza por el biologicismo, que constituye la base de la fundamentación del diagnóstico y el tratamiento y es el principal punto de diferenciación con las otras formas de atención, y por la exclusión de los factores históricos, sociales y culturales del PSEA(Menéndez, 1983, 2005, 2009).

\section{METODOLOGÍA}

La investigación fue realizada en los barrios de Villa 31 y Bajo Flores, dos territorios de la $\mathrm{CABA}$ con gran presencia de población de origen boliviano, cada uno con características particulares que brindaron contextos diversos a los itinerarios terapéuticos. 
De acuerdo con el Censo de Hogares y Población llevado adelante por el gobierno de la Ciudad de Buenos Aires (GCBA) en el año de 2009 en la Villa 31 y 31 bis, las personas de la Villa 31 nacidas en el extranjero superan la mitad de la población (51\%) mientras que los nativos de la CABA solo llegan al 29\%. El remanente (20\%) es nacido en el resto del territorio de nuestro país. Estos datos hablan de una población predominantemente migrante, prácticamente la totalidad $(99,3 \%)$ proveniente de tres países: Paraguay $(47,3 \%)$, Bolivia $(33,9 \%)$ y Perú $(19,1 \%)$. Si discriminamos el país de nacimiento entre los extranjeros, debemos señalar que el colectivo mayoritario de la Villa 31 ha nacido en Bolivia (15,5\%), seguido por los nacidos en Paraguay $(13,1 \%)$ y en el Perú $(6,1 \%)$.

Los establecimientos del sistema público de salud de la CABA correspondientes al barrio son los CeSAc (centro de salud y acción comunitaria) $\mathrm{N}^{\circ} 21$ y $\mathrm{N}^{\circ}$ 25, y los hospitales generales de agudos Bernardino Rivadavia y Juan Fernández. Además, también se encuentra el centro de atención primaria de la salud (CAPS) Ramón Carrillo, dependiente del Ministerio de Salud de la Nación.

Para caracterizar sociodemográficamente al Bajo Flores utilizaremos, dado que no pudimos hallar datos con menor nivel de agregación, los datos del Censo Nacional de Población del año 2010 correspondientes a la Comuna 7, que incluye los barrios de Flores y Parque Chacabuco. Un 81,4\% de la población es nacido en nuestro país y un 18,6\% en el extranjero. Entre estas últimas, el 47,8\% son personas nacidas en Bolivia, el 12,9\% en el Perú y el 12,1\% en Paraguay.

Los efectores del sistema público de salud presentes en el barrio son los CeSAc $\mathrm{N}^{\circ} 19, \mathrm{~N}^{\circ} 20, \mathrm{~N}^{\circ} 31$ y $\mathrm{N}^{\circ} 40$, y el hospital general de agudos Parmenio Piñero.

La población de ambos barrios es mayoritariamente joven, en edad económicamente activa y bajo nivel de instrucción formal.

Por un lado, la presencia de gran cantidad de talleres textiles clandestinos en el Bajo Flores imprime su estampa en la realidad del barrio y en cuestiones relacionadas con la salud: las experiencias de las mujeres a poco de llegar al país, la situación de explotación, las condiciones de trabajo y su impacto en la salud, la tuberculosis, etcétera (la mayoría de las entrevistadas relataron sus experiencias en talleres de costura como primer trabajo). Por otro lado, en la Villa 31 registramos, a partir de nuestras conversaciones informales con personas del barrio y con las mujeres entrevistadas, una situación de violencia mucho mayor de lo que percibimos en Bajo Flores: rivalidades entre vecinos de diferentes nacionalidades, bandas que trafican drogas en el barrio con connivencia policial, asaltos y robos, desalojos compulsivos a punta de pistola, etcétera, especialmente en las horas de mayor oscuridad del día, entre el anochecer y el amanecer. Esto restringe las 
posibilidades de tránsito por el asentamiento durante ese lapso, que justamente es en el cual los vecinos se acercan a los centros de salud para solicitar los turnos o salen del barrio para ir a trabajar. El anegamiento de calles y pasajes los días de lluvia complica aún más la circulación.

Estos territorios presentan también algunas diferencias estructurales que permitieron investigar los recorridos en situaciones diversas. La Villa 31 es un asentamiento de traza irregular, sin medios de transporte en su interior y sin ningún efector presente en el barrio en horario nocturno (el CAPS Ramón Carrillo del barrio no atiende por la noche). Dentro del Bajo Flores se encuentra la Villa 1-1114, pero ninguna de las entrevistadas vive en ese asentamiento, sino que residen en el sector del barrio con traza tradicional y que cuenta con medios de transporte y hospitales con servicio de guardia. Estas disparidades estructurales configuran distintas relaciones con la espacialidad y de vecindad para sus habitantes.

Al momento de definir qué tipo de problemas de salud se investigarían en los itinerarios terapéuticos, intentamos identificar los problemas de salud más frecuentes entre las mujeres migrantes de origen boliviano en la CABA relevando diversas fuentes de datos en las que no encontramos información específica sobre la población migrante ${ }^{1}$.

Esto es congruente con lo sostenido por Cerruti (2007) y Goldberg (2009) con respecto a la ausencia de información epidemiológica específica sobre la situación de salud de la población migrante. Aún más, plantean la escasa la producción académica sobre salud y migración que incluya la voz de los propios migrantes. La mayoría de estos trabajos en la Argentina fueron escritos por Goldberg (2009, 2010a, 2010b, 2010c, 2014) Goldberg y Silveira (2013) quienes trabaja con población migrante de Bolivia, en general sobre problemáticas de salud puntuales como la tuberculosis.

\footnotetext{
EAH del GCBA de los años 2002 a 2013; las publicaciones (de 2010 a 2013) de la Dirección de Estadísticas e Información en Salud (DEIS) del Ministerio de Salud de la Nación; los análisis de situación de salud (ASIS) de la CABA de 2004 a 2006; el informe «Comunas y Regiones Sanitarias 2008», que analiza la situación sociodemográfica y las causas de la mortalidad de los distintos grupos etarios en las distintas regiones sanitarias de la CABA; y la «Sala de situación 2009 de infecciones respiratorias agudas» de la misma jurisdicción (estos tres últimos publicados por el Departamento de Epidemiología del Ministerio de Salud del GCBA). Además, se buscó información sobre motivos de consulta o egresos de los hospitales generales de agudos Dr. Juan Fernández, Bernardino Rivadavia y Parmenio Piñero, correspondientes a los barrios en que se realizaría la investigación, y en los informes anuales «Centros de Salud y cobertura porteña de salud - plan médico de cabecera» producidos por el Ministerio de Salud del GCBA.
} 
Nuestra investigación es cualitativa y su trabajo de campo se desarrolló a través de entrevistas semiestructuradas en profundidad y grupos focales, con el fin de registrar las experiencias, conocimientos, reflexiones, sentimientos y opiniones de mujeres migrantes de origen boliviano.

Nos propusimos registrar la diversidad de experiencias y explicaciones, aun en contextos sociales y geográficos compartidos, y los puntos de contacto que pudieran tener lugar, tanto dentro de cada barrio como entre cada una de ellos. El concepto de itinerario terapéutico nos permitió recuperar las alternativas de atención efectivamente utilizadas por estas comunidades y echar luz especialmente sobre aquellos recorridos que no incluyeran al sistema público de salud que, de otro modo, hubieran permanecido desconocidos. Como señalan Trad y otros (2010), se deben considerar los momentos de elaboración del diagnóstico y de tratamiento adoptadas por el doliente, analizando las interacciones entre los distintos actores (él mismo, su familia, la comunidad, los distintos curadores, etcétera) involucrados a lo largo de los recorridos, que permanecerían parcialmente desconocidos si se partiera de la perspectiva de un tipo particular de curador.

Se entrevistó a nueve mujeres, en dos encuentros de una hora de duración aproximadamente con cada una de ellas. Las entrevistas fueron realizadas en la casa de «la Norita» (nuestra informante clave en Villa 31) y en un bar en la esquina de José Martí y Avenida del Trabajo (en Bajo Flores).

La selección de los casos estuvo guiada a partir de un muestreo teórico, incluyendo los casos según su relevancia en relación con los objetivos propuestos. El tamaño final de la muestra se basó en el principio de "saturación teórica» propuesto por Glasser y Strauss, lo que implica suspender la incorporación de casos cuando estos no aportan aspectos relevantes sobre el problema de investigación (Taylor y Bogdan, 1994).

Además, se accedió a la opinión colectiva a partir de la realización de un grupo focal (compuesto por cinco personas en cada caso) en cada barrio, en una sesión de alrededor de dos horas de duración, para explorar las impresiones de las participantes, los consensos emergentes entre ellas así como el contraste de experiencias, que permitieran construir un marco de intereses y preocupaciones en común compartido en su vida cotidiana, que difícilmente puede ser articulado por un solo individuo (Trad y otros, 2010). En todos los casos se solicitó la firma de un consentimiento informado a cada una de las mujeres que accedieron a participar, garantizando la preservación de su identidad y anonimizando los datos mediante el uso de seudónimos. 
De las diecinueve mujeres participantes del estudio (todas ellas migrantes de origen boliviano mayores de dieciocho años de edad), catorce trabajan como empleadas domésticas en casas de familia, dos trabajan en costura (una en su casa y la otra para terceros, ambas de Bajo Flores) y tres no trabajan fuera del hogar: realizan las actividades domésticas en sus casas y cuidan de sus hijos o nietos.

Luego de transcribir las entrevistas, se realizó un análisis de contenido, codificando el texto en función de los elementos temáticos relevantes respecto del problema de investigación (datos sociodemográficos, trayectoria migratoria, formas de atención disponibles y problemas de salud prevalentes en Bolivia, alternativas de atención conocidas y utilizadas en cada barrio, padecimientos más frecuentes en el barrio, itinerarios terapéuticos, experiencia con los curadores, referentes sobre cuestiones de salud consultados, accesibilidad al sistema público, utilización y disponibilidad de remedios caseros y situaciones de discriminación), registrando las citas textuales correspondientes a esos elementos en cada una de las entrevistas.

Seguidamente, se realizó la lectura de cada elemento temático atravesando todos los testimonios, primero tomando las mujeres de cada barrio y, luego, en conjunto para identificar especificidades y peculiaridades, así como como rasgos compartidos.

En el apartado siguiente, señalaremos, a partir de los relatos, los aspectos relevantes señalados por Trad y otros (2010) para el estudio de los itinerarios terapéuticos, examinando el modo en que se van articulando las decisiones que constituyen la trama de los recorridos de estas mujeres a partir de las entrevistas $\mathrm{y}$ grupos focales.

\section{RESULTADOS}

\section{Factores que inciden en la toma de decisiones}

El análisis nos permitió identificar algunos factores que inciden en la elección de cierta forma de atención y aquellos que conducen a cambiar o a combinar varias de ellas. Entre ellos, el diagnóstico y pronóstico del propio afectado, su conocimiento de la disponibilidad de formas de atención, su experiencia al utilizar cada una de ellas y su evaluación del resultado obtenido resultan cruciales. Esta enumeración la realizamos con fines analíticos, ya que a lo largo de los recorridos estos ámbitos de decisión se imbrican, superponen y modifican, usualmente en reiteradas ocasiones. 


\section{El inicio de los recorridos. Malestar y diagnóstico inicial.}

La experiencia de la enfermedad, en especial cuando se trata de eventos que afectan la vida cotidiana de las personas, establece un hito que separa claramente la vida anterior al padecimiento de la que sobreviene después de él. Esto es especialmente cierto en las personas, como las protagonistas de este estudio, que dependen exclusivamente de su trabajo para sobrevivir y para mantener a sus hijos. Prácticamente la totalidad de las entrevistadas son mujeres solas, con hijos, que no reciben ayuda de sus ex parejas y que, pese a recibir algún subsidio social, dependen de su sueldo para mantener a su familia ${ }^{2}$. Es decir que, a la preocupación por el propio estado de salud, se agrega el temor por la imposibilidad de trabajar y la caída de los ingresos del hogar.

En ese contexto, muchas veces la preocupación por satisfacer necesidades primarias desplaza la posibilidad de reparar en un problema de salud. En nuestro estudio identificamos itinerarios cuyo inicio ocurre aún antes de migrar a la Argentina.

Para el caso de los itinerarios que se iniciaron en Bolivia, la primera opción, más allá del diagnóstico, es el remedio casero y la medicina tradicional ${ }^{3}$. En caso de no poder solucionar el problema de salud de ese modo, se consulta en alguna posta o centro de salud u hospital, ya que la atención en estos es paga. La opinión fue idéntica y unánime en los dos grupos focales, tanto la de quienes provenían de ciudades como la de las mujeres provenientes ambientes rurales. En el de Villa 31, Guadalupe afirmó:

El mío era un pueblo también. No tan lejos pero como veinte minutos de la ciudad. Había también la posta de salud. Solamente funcionaba de ocho a doce y por la tarde, si te pasa algo, un chico con fiebre algo, ahí al lado había una clínica privada y si era algo más complicado había que ir al hospital. Igual por más que era un hospital o algo, tenías que pagar la internación, la cama, una jeringa, alguien que te lo inyecte... hay que pagar todo.

2 Este rol activo e independiente contrasta, tal como señala Magliano (2009), con cierto estereotipo de la mujer migrante boliviana que predomina en discursos, prácticas y políticas, asociado a la pasividad, la dependencia y la vulnerabilidad.

3 Con este término nos referimos a las prácticas de atención de la salud por personas que no son las reconocidas por el sistema oficial de salud, eso es, los ámbitos biomédicos de atención. En general, se trata de «curadores» o terapeutas cuyas prácticas tienen una tradición y adscripción cultural específicas y eficacia empírica reconocida por su comunidad. 
En algunos de los itinerarios iniciados en nuestro país, en cambio, algunas mujeres se inclinaron inicialmente por el sistema público de salud (quizás, la gratuidad de la atención favorezca esa opción o la no disponibilidad de médicos o medicinas tradicionales del país de origen).

El lenguaje utilizado para describir los síntomas y sensaciones de malestar en las sociedades con cultura científica no proviene del habla común sino del de la medicina científica, lo que determina que los médicos legitimen solo los síntomas expresados en esos términos. En los grupos focales realizados en ambos barrios, todos estuvieron de acuerdo y aportaron testimonios. Decía Norita, en Villa 31: «A mí no me pasó, pero a mi suegra sí. Decía vinagrera por la acidez... sí, y yo le tenía que explicar al médico. Hacía de traductor, porque viste que cada uno tiene su jerga, su forma de hablar...».

$Y$ esa misma distancia cultural y social es la que la que impide estas mujeres comprender las descripciones que hacen los médicos de los procedimientos que van a indicar o el modo en que se debe tomar determinada medicación. El relato de Clodivina demuestra estas dificultades en el entendimiento entre los médicos y los migrantes:

[...] A veces no le entendía. Muchas veces le decía con miedo: «Vuelva a repetirme, por favor». Con mi cara y diciendo por favor, ya me fui comprándolos. Después me decían «Ay, a vos ya te conocemos» [...] No, no nos entendíamos. Porque diferente nombre... decimos eso, es otra cosa. No nos entendemos ni hasta ahora mucho. Yo le dije: «Explícame bien». «Ya, vos nomás vení tal día, tal día», me dice. A veces se ríe nomás. A veces no le entiendo, le digo: «QQué me has dicho, doctor?». Y él se ríe nomás. Después yo ya no puedo preguntar. Si voy a insistir no me va atender más. A veces me explica, pero a veces no me explica porque no nos entendemos.

Al respecto, Jelin (2007) plantean que la actitud de los médicos del sistema público frente a esta dificultad en la comunicación compone un arco que va desde el tratar de seres inferiores a los pacientes de origen boliviano y sostener apreciaciones racistas, hasta la sensación de angustia y frustración por no saber cómo intervenir eficazmente.

\section{Alternativas de atención conocidas: el abanico de soluciones posibles}

Con respecto al conocimiento de las alternativas de atención disponibles en cada territorio, la circulación de información entre familiares, vecinos, amigos y «paisanos» es el medio más frecuente de acceso a la información. Tal fue el caso de 
Elisa, cuando su amiga Juliana la ayudó con su hija: «Juliana fue la persona que más me ayudó. Ella incluso la llevó a otro hospital, ella le llevó (...) Viajaron en tren. No sé qué hospital será $[\ldots]$...

Y el de Clodivina cuando, al poco tiempo de haber llegado de Bolivia y ante su desconocimiento, unas vecinas la orientaron para llegar al hospital Piñero: «Primero el Piñero. Me indicaron señoras que nos encontramos. “¿Por qué 1loras?". "Mi pierna, me duele". "Andá a tal". No conocía. Era a cuatro cuadras y así al final ya conocía ya. De ahí me mandaron a Álvarez. No conocía, ahora conozco Álvarez».

En ocasiones, también se llega por derivación desde el centro de salud hacia un hospital, o entre hospitales. No registramos referencias que relacionaran la biomedicina con especialistas de medicina tradicional o viceversa, ni de estos últimos entre sí. De todos modos, con frecuencia las derivaciones entre efectores del sistema público de salud son problemáticas. Así fue en el caso de Clodivina, quien luego de una severa infección en una de sus caderas requería un injerto óseo, fue derivada de un hospital a otro.

Me dijo: «No, señora. Tu cadera está mal, mal. Tenés que ir a algún hospital ¿Cuál querés? ¿Fernández o Álvarez?», me dijo. Y yo le dije: «¿Cuál me queda cerca?». Como no conocía tanto. «Te queda Álvarez», me dijo. «Entonces ahí ándate señora, porque tiene banco de hueso. A vos te falta huesos», me dijo. «En Piñero no tenemos banco de huesos», me dijo. Entonces ahí yo me fui al Álvarez [...] Cuando fui a presentarme a ese turno, fui al Pabellón I, Traumatología, y me dijo: «No, no. Adonde te han atendido andá hacete atender», $[\ldots]$ los médicos. Y le dije «Ya no me quieren atender, porque falta el hueso, no tiene hueso». Ahí... nada. Nada, no me daban atención.

Es usual, de acuerdo con los testimonios recogidos, que las personas migrantes consulten al farmacéutico apelando a su «conocimiento médico», como un modo de salvar los obstáculos que se presentan en el acceso a la atención en el sistema público. Florencia, ante una conjuntivitis persistente y luego de haber consultado en el hospital Rivadavia, se acercó a la farmacia: «Después de eso, todavía tenía el ojo rojo, rojo, rojo, todo... lo blanco que tenemos, tenía rojo, rojo... y como hay que madrugar para ir al hospital no fui más al hospital... y en la farmacia nomás, pregunté y era... me dieron un descongestivo en gotas».

Ante la dificultad para conseguir turnos y la necesidad de madrugar (siendo madre sola no tiene con quien dejar a su hijo), Juliana consulta al farmacéutico usualmente: "Cuando me duele la panza... entonces me hago un mate o una tableta... me voy a la farmacia y le digo "Me duele el estómago" y pregunto 
[...] "Sertal ${ }^{\circledR} "$, me dicen. Tomo [...] si no me calma... Me voy a la salita... O si no al hospital directamente porque la salita mucho tampoco no... no te dan nada... ¿viste?»

Como se aprecia, se trata de una estrategia para minimizar las complicaciones y demoras en el acceso, elaborada en función de la propia experiencia.

En otras ocasiones, la visita en la farmacia está orientada por la búsqueda de una solución a un problema de salud luego de haber fracasado con alguna forma de atención. La hija de Elisa fue internada en el hospital Ramos Mejía luego de haber sufrido un traumatismo en el cráneo, asociado a esto aparecen vómitos persistentes:

Del hospital Ramos Mejía, al frente, yo me fui, le pregunté... a la farmacéutica, entonces $[\ldots]$ «Disculpe» $[\ldots]$ «Yo tengo... tengo a mi hija ahí internada», le digo, «pero está vomita y vomita» [...] Le pregunté si yo podía darle algún medicamento o algo para que pare. Me dijo. «Lo que tiene que hacer es preguntarle a su médico». «Pero ya le pregunté y me le pusieron suero», le dije [...] Pero le calmó... ¿no le digo que está viniendo [vomitando] como tal? pero siempre está viniendo [vomitando] cada diez o quince minutos [...]», le digo. «Y tengo miedo», le digo. Entonces me dijo: «Bueno, te voy a dar un medicamento, pero vos no digas nada a nadie. ¿Me estás escuchando?». «Sí», le digo. «Agarrá y dale con agua». Gotitas. Bueno, agarré y el doctor me había dicho que ella [...] mientras estaba vomitando no podía recibir nada. Que no le dé nada. Pero agarré, le llevé el agua, le di las gotitas... No sé si eso o qué o el suero, [...] como a las dos horas... así... dejó de vomitar. Ella había dicho que yo le de quince gotas y yo le di veinticinco gotas $[\ldots]$.

Otra de las opciones disponibles dentro del paradigma biomédico es el de los consultorios privados atendidos por médicos de origen boliviano ${ }^{4}$. Solo una de las

4 El auge de este tipo de consultorios tuvo lugar en momentos en que en los hospitales del sistema público de salud se exigía a los migrantes el documento nacional de identidad (DNI) argentino para brindarles atención y en la que la discriminación y el maltrato eran moneda corriente. Luego de la sanción de la nueva Ley de Migraciones $N^{\circ} 25.781$ que avanzó en la garantía de derechos a los migrantes a punto de prácticamente igualarla a la de los nativos, esa exigencia dejó de existir. Análogamente, a partir del nuevo marco legal y de las reiteradas denuncias de organizaciones sociales, las situaciones de discriminación en un primer momento se sofisticaron (por ejemplo, se dejó de negar la atención, pero se hacía esperar a los migrantes a que se atendieran primero todos los nativos, aun cuando ellos hubieran llegado más temprano) y, gradualmente, se van reduciendo a casos aislados. Sospechamos que es por esta flexibilización en las condiciones de accesibilidad que los centros médicos privados atendidos por profesionales de origen boliviano fueron perdiendo gravitación. 
entrevistadas manifestó haberla utilizado, y lo hizo por desconocer la gratuidad de la atención en el sistema público. Recordó Clodivina: «Otro allá, cuesta, pero plata. No es Santojanni, más allá en Liniers, es particular, un consultorio. San Salvador [...] Fui primera vez ahí, pero todo mi sueldo y nomás ahí. Y no. [...] No pensaba que era gratis hospital».

Al indagar sobre la presencia de especialistas en medicina tradicional, ninguna de las entrevistadas en el Bajo Flores manifestó conocer alguno en el barrio. Las que tuvieron consultas con curanderos, lo hicieron en otro barrio de la CABA (Liniers) o en alguna localidad del AMBA (Villa Celina). En el caso de la Villa 31, la mayoría de las señoras consultadas sabían de la presencia de algún curador (tanto de origen boliviano como paraguayo) y dónde encontrarlo, aunque no todas utilizaron esa forma de atención. Es interesante señalar que algunas de las participantes de la investigación acudieron a especialistas de origen paraguayo, o incluso recurrieron tanto a bolivianos como paraguayos lo que indica que, más que una adscripción a la medicina tradicional andina o la búsqueda de las formas de atención que utilizaban en Bolivia, hay una motivación más pragmática: la solución a su problema de salud, que supera cualquier diferencia o incompatibilidad que pudiera existir entre diversas formas de atención (Menéndez, 2003).

Sería interesante dilucidar los motivos que explican la diferencia entre los barrios investigados con relación al conocimiento de especialistas en medicina tradicional. Nos preguntamos si la mayor cercanía y estrechez de las relaciones de vecindad en Villa 31 favorecen la circulación de esa información.

Al iniciar la investigación, sospechábamos que la antigüedad de la residencia en nuestro país sería una variable importante relacionada con el conocimiento de alternativas de atención disponibles. Sin embargo, descubrimos que más importante aún es el acceso a redes de contacto en las que se acumula y circula esa información. Tal como señalamos anteriormente, la primera consulta de Clodivina en nuestro país fue en un centro médico particular atendido por profesionales de Bolivia, ya que, pese a llevar casi un año viviendo en la Argentina, no sabía de la gratuidad de los servicios públicos de salud. Lucinda, en cambio, pese a contar solo con dos semanas de residencia en la Villa 31, pudo atenderse en un centro de salud, en un hospital y realizarse estudios complementarios por contar con la guía de sus hermanas, antiguas vecinas del barrio, que la condujeron a lo largo de su recorrido. Esto es consistente con lo que señalan Jelin (2007) sobre el modo en que la información sobre médicos e instituciones más amigables circula entre las personas migrantes, permitiéndoles identificar los sitios en que tienen mayores probabilidades de ser aceptados. Las redes de parentesco o sociales son 
fundamentales para acceder y transitar por el sistema de salud, como plantean Martins (2008) y Venturiello (2012).

\section{Las experiencias: la relación con los curadores y las situaciones de atención}

Una vez iniciado el recorrido en busca de atención, las personas entran en contacto con los curadores (en el caso de la biomedicina, también con el personal administrativo, de enfermería, etcétera). Esos intercambios van moldeando experiencias, reflexiones y sentimientos, que muchas veces determinan la continuidad con determinada forma de atención o el cambio de rumbo del itinerario.

Alina, de la Villa 31, se percató de que un curador tradicional en Bolivia estaba alcoholizado y decidió suspender la consulta: «[...] Yo no creía nada... Porque estaba con dolor. Yo le dije: "Ya está", le dije. El hombre estaba borracho... se tomó... Sí, estaba re borracho. Y le dije: "No sabe nada", le dije a mi marido». En la experiencia de Elisa en un hospital de la CABA donde fue internada su hija, tanto la relación con el personal como las condiciones estructurales del nosocomio, la llevaron a pensar en trasladarla:

Yo por eso, en fin, le dije: «Quiero llevármela al hospital Rivadavia. Quiero irme». Y me decían: «No. Así no tenemos que moverla, usted no entiende». «Pero si acá no le están haciendo nada». «No, espere... espere... nosotros tampoco tenemos una varita $[\ldots] »$. Bueno. Esperaba ahí $[\ldots]$ Y ella que... aparte de estar ahí bastante gente porque... o sea, que no estaba en una sala o en un cuarto. Estaba en un pasillo, donde estaban... supongo que estaba toda la gente de emergencias [...] entró un chico que se había chocado con la moto, estaba todo hecho bolsa. Después entró una señora igual... o sea había un montón... mi hija veía gente lastimada y eso [...] Ay, no... y había dos viejitas... yo vi todo eso... no, horrible... para mi hija, ver esas cosas, como que era también... decía: «iQuiero irme, quiero irme!».

En ocasiones, las prácticas del sistema de salud oficial están reñidas con las costumbres de estas mujeres en su lugar de origen, lo que da lugar a experiencias angustiantes. Este tema surgió específicamente en el grupo focal que realizamos en Bajo Flores. Todas las mujeres confesaron haber nacido en la casa de sus familias $\mathrm{y}$, muchas de ellas, haber dado a luz a sus hijos en sus hogares ayudadas por sus madres o alguna mujer mayor, y en posición de cuclillas. Es por ello que para ellas es extraño tener sus hijos en el hospital, algo muy alejado de sus costumbres: las desnudan, las acuestan, las pinchan y se sienten maltratadas. Ninguna manifestó preferencias en el caso de atenderse con médicos en general, pero todas 
expresaron su predilección por las médicas en el caso de las consultas al servicio de ginecología. Jelin (2007) señalan las diferencias culturales relacionadas con prácticas y conductas que inciden sobre la atención registradas en su trabajo de campo: la posición para el parto (las mujeres bolivianas prefieren parir de cucli1las), la lactancia (para estas mujeres, no necesariamente es la madre quien debe amamantar al bebé), rechazo a la cesárea - aun cuando no hacerlo signifique riesgo de vida para la madre o el feto-, el valor de la placenta (especialmente en la cultura aimara recibe un tratamiento especial: es lavada y observada en detalle, ya que se cree que se cree que encierra detalles sobre el futuro del recién nacido; luego es enterrada cerca del hogar), rechazo a las extracciones de sangre, vestimenta (estas mujeres llevan varias capas de ropa, ya que el momento del parto se asocia con la «apertura de la matriz» que puede «dejar entrar frío» o que »se enfríe la sangre»), pudor para desvestirse, hábitos de higiene y el sometimiento a sus maridos, quienes cuestionan la duración de las internaciones y reclaman el alta de la mujer para que vuelva a trabajar. Los médicos entrevistados en esa pesquisa consideran algunas de estas conductas como peligrosas y, aunque otras no implican riesgo, no son bien vistas desde el modelo biomédico.

Las experiencias con el sistema público de salud van forjando estrategias para sortear las dificultades que suelen presentarse y consolidan preferencias por determinadas instituciones y profesionales. En el grupo focal realizado en Villa 31, todas estuvieron de acuerdo con Elena cuando afirmó: «En Banderita (CeSAC $\left.\mathrm{N}^{\circ} 25\right)$ también es lindo. Ese también es bueno. Es mejor que el de Coto (CeSAC N $\left.{ }^{\circ} 21\right) »$. Cuando llegó el turno de los hospitales, la gran mayoría prefirió el hospital Rivadavia al hospital Fernández. Este consenso mayoritario da la pauta de que, más allá de cualquier experiencia personal, existen diferencias marcadas entre servicios, profesionales y hospitales.

Desde la mirada de los profesionales del sistema público de salud, las principales quejas expresadas se relacionan con la predisposición a la consulta por el servicio de guardia por parte de los migrantes, el estado crítico de salud con que llegan muchos de ellos a nuestro país (situación que se ven obligados a resolver en contextos de exceso de trabajo), las trabas en el entendimiento y la comunicación y la falta de cumplimiento de las indicaciones y tratamientos (Jelin, 2007).

Más allá de las vivencias y reflexiones del propio enfermo, es importante la opinión de su círculo de allegados en la toma de decisiones relativas a los itinerarios terapéuticos. Pero encontramos también que los pareceres de otros pacientes (especialmente si son de origen boliviano), circunstanciales compañeros 
en las salas de espera de hospitales y centros de salud inciden sobre sus juicios y acciones. Comentó Elisa:

Sí... ahí las mismas señoras que venían, los pacientes me decían: «Llevátelo a otro hospital. Porque acá no te lo van a atender. Estás viendo cómo está. Llevátela [...] al Fernández o al Rivadavia. Decile que te den el traspaso [...] Este me parece que es el peor hospital que hay», me dijeron. "Siempre me mandan a mí. Porque vivo acá», me dijo una señora. Era paisana también $[\ldots]$.

\section{La evaluación del devenir de los problemas de salud}

La evaluación, finalmente, refiere a la valoración que hacen quienes sufren una enfermedad acerca de la evolución de su padecimiento y de la eficacia del tratamiento instituido luego de haber consultado con un especialista. Cabe aclarar que refiere a la percepción subjetiva de esa evolución y eficacia que se relaciona, en general, con la sensación de mejora en los síntomas. Sin embargo, no pocas veces, el alivio en la sintomatología no significa un avance en la curación y, viceversa, en ocasiones, determinados tratamientos producen malestares transitorios antes de restituir la salud. Tal como señalan Kleinman, Eisenberg y Good (1978), el padecimiento puede ocurrir en ausencia de enfermedad en términos biomédicos y el curso de una enfermedad es distinto de la trayectoria del padecimiento que la acompaña.

Una de las evaluaciones en el itinerario de Alina, cuando tomó una medicación que le vendió una vecina paraguaya, ilustra sobre la valoración positiva de una mejora transitoria que no significa un avance en la curación: «[...] Me lo tomé un poquito, estaba así así, poco a poco el dolor todito se me fue, no tenía nada de dolor, ni en las manos, ni en la cabeza. Sanita, sanita. Me empecé a ayudar, a hablar con ellos, todo. "Se me fue esa pastilla lindo", le dije, "Me hizo todo bien", le dije a mi marido. "No me duele nada", le dije».

Sobre el final de su itinerario, encontramos la situación opuesta: el malestar transitorio provocado por una reacción alérgica a un medicamento para tratar su enfermedad. Luego de haber recibido el alta, tuvo que volver al hospital: «[...] de ahí salí... volví otra vez me interné... Me salió unos granos todo acá... Todas las piernas hasta la espalda... Todo ampollas pero grandes... y que era eso de medicamento...».

En los testimonios recopilados, registramos evaluaciones positivas y negativas tanto de la biomedicina como de la medicina tradicional y el modo en que esas 
estimaciones definieron el rumbo de los itinerarios. A modo de ejemplo de una evaluación negativa, incluimos la experiencia de Clodivina con un curandero en el barrio de Liniers:

Uno también en Liniers era. «Seiscientos pesos dame, y yo te lo voy a hacer volver a tu marido». Y fui a regalar seiscientos pesos [...] Fui a reclamar. Le dije: «Mirá, me has dicho que iba a volver mi marido». «Ah, no. Esperale dos semanas más. Ya va a venir» [...] jajaja... Es mentira. Para curarme era también. Me dijo: «Ya te vas a mejorar. Vos no tengas miedo que ya te vas a curar». Es por bajarte plata nomás que ellos hacen...

Entre las evaluaciones positivas podemos señalar la de Alina, quien estuvo al borde de la muerte en el hospital Fernández. A partir de su enfermedad y de la internación que trajo aparejada, Alina consolidó una relación con la médica que la atendió: "Ya tengo mi médica... me conoce. Sí, me atendieron bien. Ahora me atienden bien... la doctora que tengo... Es la que me controla siempre... Cualquiera cosa me pase el dolor... ella me dice que le llame cualquier rato... tengo su teléfono...».

Otra valoración positiva, en este caso para un curador tradicional, fue la de la propia Alina hacia un curandero paraguayo de la Villa 31. Luego de recibir el alta, fue a su casa a visitarlo. Recuerda: «Sí, sí. Cuando yo salí de hospital fuimos de vuelta conmigo a su casa. Y me dijo que me voy a poner bien, mejor, poco a poco. Que no hagas más nada y que siga el tratamiento. Es un señor mayor... Sentía bien con él, con lo que me decía». La confianza en el otro aparece como un elemento fundamental en ambos casos.

\section{COMENTARIOS FINALES}

Nuestro trabajo con las mujeres migrantes de origen boliviano en los barrios estudiados nos permitió acceder a las prácticas de salud que ocurren por fuera de los servicios públicos. A partir de sus relatos, constatamos el uso articulado de las distintas alternativas de atención que, como señala Menéndez (2003, 2005, 2009), hubieran permanecido desconocidas si hubiéramos partido del testimonio de los curadores o del sector salud, para contactar a las mujeres. Ante diferentes episodios de enfermedad se consulta a efectores del sistema público de salud de distinto nivel (centros de salud, hospitales, etcétera), consultorios privados atendidos por médicos de la comunidad boliviana y curanderos en el AMBA y en Bolivia. Debemos remarcar la ausencia de cobertura por obra social de estas 
mujeres, aun cuando muchas de ellas manifestaron tener trabajo, lo que es un claro indicador de la precariedad de las condiciones de contratación laboral.

La reconstrucción de los itinerarios terapéuticos a partir de narraciones de sus protagonistas evidencia la existencia de una vasta variedad de formas de atención, fundadas en diversas explicaciones de la salud y la enfermedad, cada una con su propia lógica de intervención sobre los padecimientos, sin generar conflictos o contradicciones imposibles de afrontar. Además, nos permitió analizar algunos de los factores que intervienen en la toma de decisiones sobre diversas formas de atención.

La percepción inicial del malestar, las acciones iniciales para lograr la recuperación y la consulta con algún curador especializado están moldeadas por el contexto sociocultural de las personas. La circulación de información entre familiares, vecinos, amigos y «paisanos» es el medio más frecuente de acceso a información sobre las alternativas de atención disponibles en cada territorio. Para el caso específico de los itinerarios terapéuticos iniciados en Bolivia, la opinión de las mujeres entrevistadas como la de quienes participaron de los grupos focales fue unánime: la primera opción es siempre la autoatención con algún remedio casero o la consulta con algún medico tradicional, argumentando que la atención en el sistema oficial de salud es paga. En contraste, en los itinerarios que se inician en Argentina, aparecen consultas a los servicios del sistema público desde el inicio de los recorridos, puede que influya la gratuidad de esa atención como la escasez de recursos médicos tradicionales que sean una alternativa aceptable culturalmente. En ese contexto, las mujeres de origen boliviano muchas veces se ven enfrentadas a prácticas y situaciones que están reñidas con sus costumbres y creencias que, en ocasiones, pueden determinar que desistan de continuar con cierto procedimiento o tratamiento. Así, las experiencias con el sistema público de salud van forjando estrategias para sortear las dificultades que suelen presentarse y consolidan preferencias por determinadas instituciones y profesionales.

A modo de cierre, cabe señalar el valor de los hallazgos presentados para pensar y valorar modalidades de atención e inclusión de la población al sistema público de salud, garantizando derechos - atentos a sus estrategias tradicionales - de modo tal que se potencie la resolución de los problemas de salud en este colectivo migrante, mayoritario en el área donde desarrollamos nuestro estudio. Asimismo, cabe destacar el valor de la estrategia teórico-metodológica aplicada: «itinerarios terapéuticos», cuyo potencial puede extenderse a otros grupos poblacionales migrantes, ya sea en la Argentina o de otros países. Por último, los resultados permiten elaborar hipótesis para el trabajo con otras minorías migrantes ya sea en la argentina como en otros países de la región. 


\section{REFERENCIAS}

Cabral, Ana Lucía Lobo, Angel Martínez-Hernáez, Eli Iola Gurgel Andrade y Mariangela Leal Cherchiglia (2011). Itinerários terapêuticos: o estado da arte da produção no Brasil. Ciencia \& Saúde Coletiva, 16(11), 4433-4442. https://doi.org/10.1590/ S1413-81232011001200016

Cerrutti, Marcela (2007). Problemas de salud, utilización de servicios y conductas preventivas de los migrantes limítrofes en la Argentina. En E. Jelin (dir.), Salud y migración regional. Ciudadanía, discriminación y comunicación intercultural. Buenos Aires: IDES.

Dirección General de Estadísticas y Censos de la Ciudad Autónoma de Buenos Aires (DGEyC). (2009). Censo de Hogares y Población. Villas 31 y 31 bis. Buenos Aires: Autor.

Gerhardt, Tatiana Engel (2006). Itinerários terapêuticos em situações de pobreza: diversidade e pluralidade. Cadernos de Saúde Pública, 22, 2449-2463. https://doi. org/10.1590/S0102-311X2006001100019

Goldberg, Alejandro (2009). Salud e interculturalidad: aportes de la Antropología Médica para un abordaje sociosanitario de la población boliviana de la Ciudad Autónoma de Buenos Aires. Temas de patrimonio cultural. Recuperado de http:// estatico.buenosaires.gov.ar/areas/cultura/cpphc/archivos/libros/temas_24.pdf

Goldberg, Alejandro (2010a). Abordaje antropológico comparativo en torno a la incidencia del Chagas y la tuberculosis en inmigrantes bolivianos residentes en Barcelona y Buenos Aires, respectivamente. Revista de Humanidades Médicas \& Estudios Sociales de la Ciencia y la Tecnología, 3, 1-18.

Goldberg, Alejandro (2010b). Factores socioculturales en el proceso asistencial de pacientes con tuberculosis en el Instituto Vaccarezza del Hospital Muñiz, 2009. Revista Argentina de Salud Pública, 1(5), 13-21.

Goldberg, Alejandro (2010c). Tuberculosis en inmigrantes bolivianos del Área Metropolitana de Buenos Aires: narrativas y procesos asistenciales. En A. Martínez Hernáez y S. Di Giacomo (comps.), De la evidencia a la narrativa en la atención sanitaria: biopoder y relatos de aflicción (pp. 113-136). Tarragona: Publicaciones Universidad Rovira y Virgili, Colección de Antropología Médica.

Goldberg, Alejandro (2014). Trayectorias migratorias, itinerarios de salud y experiencias de participación política de mujeres migrantes bolivianas que trabajaron y vivieron en talleres textiles clandestinos del Área Metropolitana de Buenos Aires, Argentina. Anuario Americanista Europeo, 11, 199-216.

Goldberg, Alejandro y Cássio Silveira (2013). Desigualdad social, condiciones de acceso a la salud pública y procesos de atención en inmigrantes bolivianos de 
Buenos Aires y Sao Paulo: una indagación comparativa. Saúde e Sociedade, 22(2), 283-297. https://doi.org/10.1590/S0104-12902013000200003

Instituto Nacional de Estadísticas y Censos (INDEC) (2010). Censo nacional de población. Recuperado de http://www.censo2010.indec.gov.ar/index_cuadros.asp

Jelin, Elizabeth (dir.) (2007). Salud y migración regional. Ciudadanía, discriminación y comunicación intercultural. Buenos Aires: IDES.

Kleinman, Arthur, Leon Eisenberg y Byron Good (1978). Culture, illness and care. Clinical lessons from anthropologic and cross-cultural research. Annals of Internal Medicine, 88, 251-258. https://doi.org/10.7326/0003-4819-88-2-251

Magliano, María José (2009). Migración, género y desigualdad social. La migración de mujeres bolivianas hacia la Argentina. Estudos Feministas, 17(2), 344-367. https://doi.org/10.1590/S0104-026X2009000200004

Martins, P. H. (2008). Usuários, redes de mediadores e associações públicas híbridas na saúde. En R. Pinheiro y R. A. Mattos (orgs.), Cuidar do cuidado: responsabilidade com a integralidade das ações em saúde (pp. 115-142). Río de Janeiro: CEPESC.

Mattosinho, Mariza Maria Serafim y Denise Maria Guerreiro Vieira da Silva (2007). El itinerario terapéutico del adolescente con diabetes mellitus tipo I y sus familiares. Revista Latino-Americana de Enfermagem, 15(6). https://doi.org/10.1590/ S0104-11692007000600009

Menéndez, Eduardo (1983). Modelo hegemónico, modelo alternativo subordinado, modelo de autoatención. Caracteres estructurales. En Eduardo Menéndez, Hacia una práctica médica alternativa. Hegemonía y autoatención (gestión) en salud. México DF: CIESAS.

Menéndez, Eduardo (1994). La enfermedad y la curación ¿Qué es la medicina tradicional? Alteridades, 4(7), 71-83.

Menéndez, Eduardo (2003). Modelos de atención de los padecimientos: de exclusiones teóricas y articulaciones prácticas. Ciencia \& Saúde Coletiva, 8(1), 185-207. https://doi.org/10.1590/S1413-81232003000100014

Menéndez, Eduardo (2005). Intencionalidad, experiencia y función: la articulación de los saberes médicos. Revista de Antropología Social, 14, 33-69.

Menéndez, Eduardo (2009). De sujetos, saberes y estructuras. Introducción al enfoque relacional en el estudio de la salud colectiva. Buenos Aires: Lugar Editorial.

Merino, Maria de Fátima Garcia Lopes y Sônia Silva Marcon (2007). Concepções de saúde e itinerário terapêutico adotado por adultos de um município de pequeno porte. Revista Brasileira de Enfermagem [online]. 60(6), 651-658. https://doi. org/10.1590/S0034-71672007000600007 
Perdiguero, Enrique y Beatriz Tosal (2007). Las medicinas alternativas y complementarias como recurso en los itinerarios terapéuticos de las mujeres. Feminismo/s, 10, 145-162. https://doi.org/10.14198/fem.2007.10.10

Taylor, S. y R. Bogdan (1994). Introducción a los métodos cualitativos de investigación. La búsqueda de significados. Barcelona: Paidós.

Trad, Leny Alves Bonfim, Jeane Saskya Campos Tavares, Carla Silva Soares y Rachel Coelho Ripardo (2010). Itinerários terapêuticos face à hipertensão arterial em famílias de classe popular. Cadernos de Saúde Pública, 26(4), 797-806. https:// doi.org/10.1590/S0102-311X2010000400021

Venturiello, María Pía (2012). Itinerarios terapéuticos de las personas con discapacidad y mediaciones en el cuidado de la salud: la mirada de los familiares. Physis Revista de Saúde Coletiva, 22(3), 1063-1083. https://doi.org/10.1590/S010373312012000300012 